\title{
The Effect of Mineral Powder on the Surface/Interface of Aggregates and Asphalt
}

\author{
Peng Tian ${ }^{1}$, Kaixing Peng ${ }^{1}$, Hangning Dong ${ }^{1}$, Yan $_{\mathrm{Li}^{2}}$, Weizhi Dong ${ }^{1}$ \\ ${ }^{1}$ School of Transportation Science and Engineering, Jilin Jianzhu University, Changchun 130118, China \\ ${ }^{2}$ Changchun Sino-german Orthopaedics Hospital, Changchun 130051, China
}

Corresponding Author Email: Dongweizhi@jlju.edu.cn

https://doi.org/10.18280/acsm.450403

Received: 26 April 2021

Accepted: 2 July 2021

\section{Keywords:}

asphalt mixture, surface and interface effect, adhesion, mineral powder, microscopic image

\begin{abstract}
This paper attempts to analyze the effect of mineral powder on the adhesion of aggregates and asphalt. First, it employs the gravimetric method to quantitatively analyze the peeling rate of asphalt and asphalt mortar from the surface of basalt, andesite, and limestone aggregates. Then, it takes microscopic pictures of the mineral powder adhered on the surface of the aggregates to observe the distribution of mineral powder in the asphalt mixtures, and uses profiles to analyze the adhesion status of mineral powder on the surface of the aggregates. At last, this paper analyzes the effect of mineral powder particles on the surface/interface of the aggregates and asphalt, and the results indicate that mineral powder has increased the roughness of the surface of the aggregates, therefore it indirectly promotes the adhesion of asphalt on the surface of the aggregates; the mineral powder particles interact with the surface texture of the aggregates, forming an embedding and wedging structure in the texture; compared with aggregates with smooth surface, the adhesion promotion effect is stronger.
\end{abstract}

\section{INTRODUCTION}

Water damage is one of the major causes for the early damage of asphalt pavement. The invasive water would separate the adhesion interface between the asphalt and the aggregates, which is the main reason of the destroy of adhesion of asphalt on aggregate surface [1]. The adhesion of asphalt on the surface of crushed stones (aggregates) is a key index to evaluate the water damage resistance of asphalt mixture pavement [2]. The water damage of asphalt mixtures is divided into two stages: first, the invasive water separates the adhesion interface of asphalt and aggregates, destroying the adhesion of asphalt on the surface of the aggregates; second, the interface of invasive water continues to expand, and the damage surface continues to expand, destroying the adhesive force between the asphalt mixtures. In seasonal frozen soil areas, frost heave and thaw collapse have a great destructive impact on the road surface [3].

At present, improving the adhesion of asphalt on the surface of aggregates is a primary method to avoid water damage and freeze-thaw damage [4]. The properties of asphalt, the properties of aggregates, and the mixing and storage process are the three factors affecting the adhesion of asphalt and aggregates. The properties of asphalt include the its chemical composition, viscosity, and surface tension, etc.; the properties of aggregates include the chemical composition, surface structure, porosity, level of cleanliness, and surface dryness and wetness, etc. The main influencing factors of the mixing and storage process include the mixing temperature and the storage time of the hot material. The proportion of mineral powder in the asphalt mixtures is about $8-13 \%$, under the conditions that the properties of the asphalt and the aggregates are relatively stable, the mineral powder particles not only act as filler, but also have an important role in promoting the adhesion of asphalt and aggregates.
Based on water immersion experiment and the gravimetric method, this paper quantitatively analyzed the peeling rates of asphalt and asphalt mortar from the surface of basalt, andesite, and limestone aggregates. Then, by comparing the differences in the peeling rate, this paper quantitatively analyzed the positive effect of mineral powder particles on the adhesion of asphalt and aggregates. After that, through the observation of the microscopic images of plans and profiles, this paper also analyzed the working state of the mineral powder particles on the surface/interface of asphalt and aggregates. This study provided a new idea and a new method for the study of the mechanism of using mineral powder particles to improve the adhesion of asphalt mixtures.

At first, this paper elaborated on the steps of the water immersion experiment and the process of using gravimetric method to measure the peeling rates of asphalt and asphalt mortar from the aggregates, and comparatively analyzed the peeling rates of asphalt and asphalt mortar from the surface of the basalt, andesite, and limestone aggregates. Then, with the help of an electron microscope, the microstructure of asphalt mortar adhering on the surface of aggregates was observed, and the distribution of mineral powder particles in asphalt mortar was analyzed. At last, the surface/interface effect of mineral powder particles on the adhesion of asphalt and aggregates was analyzed.

\section{RESEARCH STATUS OF AGGREGATE SURFACE ADHESION}

\subsection{The adhesion principle of asphalt on the surface of aggregates}

The adhesion between asphalt and aggregates is fundamentally determined by the physical and chemical 
properties of aggregates and asphalt. In a highway construction project, the aggregate origin is often the quarry around the project, therefore, by carefully analyzing the adhesion levels of asphalt on the surface of crushed stones of different lithology types produced from different quarries, we can give full play to the best performance of the local road construction material (namely the crushed stone aggregate) [5]. Based on the properties of the crushed stone aggregates, by reasonably designing the grading scheme of the aggregates and the pavement structure, the performance of the asphalt mixtures and the quality of the road construction project could be improved.

The essence of the adhesion of asphalt and aggregates is a result of the action of surface force of asphalt and aggregates, the residual force field on the surface of the aggregates and the particles of the asphalt will attract each other [6]. Chemical reaction theory, mechanics theory, surface energy theory, surface structure theory, electrostatic attraction theory, and molecular orientation theory are often used to analyze the adhesion mechanism of asphalt on the surface of aggregates; each theory has its own characteristics, they focus on different aspects and can complement each other [7-11]. The chemical reaction theory takes the acidity and alkalinity of the stone material as the research object, generally, this theory holds that the acidic components in the asphalt will react with the alkaline active components on the surface of the aggregates, and the adhesion of the alkaline stone material to the asphalt is better than that of the acidic stone material. The mechanics theory takes the surface roughness and porosity of the aggregates as the research object, it analyzes the influence of the surface characteristics of aggregates on the adhesion at the micro level [12]. The surface energy theory evaluates the wetting level of asphalt on the surface of crushed stone flakes by measuring the wetting angle [13-15]. The surface structure theory analyzes the adhesion between aggregates and asphalt by studying the surface topographic features such as the angularity, contour, and shape of the aggregates $[16,17]$. The electrostatic attraction theory believes that when asphalt is in contact with aggregates, two layers of electrostatic attraction will be formed, and the adhesive force between the interfaces is the action force between the two layers; the asphalt mixtures can be regarded as a capacitor, which can be charged by the contact between asphalt and aggregates [18]. The molecular orientation theory holds that the level of adhesion between asphalt and aggregates depends on the directional adsorption of surface-active substances in asphalt to the surface of the aggregates [19].

\subsection{Methods for researching the adhesion of asphalt on aggregate surface}

The most common method for measuring adhesion is the water boiling method, but this method depends too much on subjective judgement therefore the empirical error is large. Another adhesion measurement method is the water immersion method which immerses the asphalt-coated sample into a constant temperature water tank at $80^{\circ} \mathrm{C}$ for 30 minutes instead of boiling it in slightly boiling water for 3 minutes. Later, based on these two methods, the gravimetric method had been developed, before and after the water boiling experiment, the sample is weighed, and the calculated asphalt peeling rate is used to replace the manual judgement method to determine the adhesion level, which can improve the objectivity of the adhesion measurement [20]. The photoelectric colorimetric method and the NAT method both use the spectrophotometer to analyze the change of asphalt concentration. The photoelectric colorimetric method converts light energy into electrical energy using a photoelectric converter to reflect the dissolution amount of peeled asphalt in water, thereby inferring the amount of peeled asphalt. The NAT method is also called the SHRP net adsorption method, this method is derived from the SHRP asphalt research project of the Highway Strategic Research Program in the United States. The NAT method realizes the replacement of asphalt and water by circulating the asphalt-toluene solution, then it uses a spectrophotometer to measure the absorbance of the solution and derive the peeling rate, adsorption rate, and other data [21]. The solvent elution method uses the flowing asphalttoluene solution to elute the asphalt on the aggregates and measures the peeling rate of the asphalt $[22,23]$. The capillary column method describes the adhesion by measuring the wetting angle of the asphalt-toluene solution to the aggregates. The non-destructive ultrasonic measurement technology can be used to evaluate the binder content of the asphalt mixtures [24].

The NAT method and the photoelectric colorimetric method have fewer human influencing factors during the experimental process, but they have a high requirement on experimental equipment and operation skills. Due to the influence of the measurement accuracy of the contact angle and the surface characteristics of the aggregates, the capillary column method is more suitable for the comparison of the adhesion performance. Hence, we can see that each method has its advantages and disadvantages. Among these methods, the gravimetric method is an upgrade of the classic experimental methods (the water boiling method and the water immersion method), its experimental process is standardized and easy to operate, therefore, this study applied it to measure the peeling rate of asphalt from the surface of the aggregates.

In engineering practice, mineral powder is an important composition of the asphalt mixtures, accounting for about 5$13 \%$, the adhesion of asphalt on aggregate surface is completed under the joint action of the mineral powder. In traditional studies, the main research objects are usually the asphalt and the aggregates, few have concerned about the filler (mineral powder), among the few existing studies, most of them focus on the influence of filler type [25, 26], dosage and distribution $[27,28]$ on the performance of the asphalt mixtures, very few studies have discussed the effect of mineral powder particles on the surface/interface of asphalt and aggregates, therefore, to fill in this research gap, this study conducted experiment on asphalt mortar peeling off from the surface of aggregates to research the relationship among mineral powder, aggregate texture, and asphalt adhesion.

\section{EXPERIMENT ON THE ADHESION OF ASPHALT AND ASPHALT MORTAR ON AGGREGATE SURFACE}

\subsection{The gravimetric method and the water immersion experiment}

Based on water immersion experiment and the gravimetric method, the peeling rate of asphalt-coated aggregates after water immersion was measured in the experiment. First, the aggregate samples to be measured were cleaned, then heated in a thermostat at $150^{\circ} \mathrm{C}$ for 30 minutes to remove the water in 
the aggregates. After that, the dried aggregates were weighed, the weight value was recorded as $W_{0}$, the aggregates and asphalt were heated to $150^{\circ} \mathrm{C}$ and fully mixed; later, the mixture was cooled at room temperature for 1 hour and weighed again, the weight value was recorded as $W_{l}$. At last, the mixture was put into a constant temperature water tank with a temperature of $80^{\circ} \mathrm{C} \pm 1^{\circ} \mathrm{C}$ for 30 minutes, then taken out and dried at room temperature for 24 hours, weighed again and recorded as $W_{2}$. The peeling rate of aggregates $P_{d}$ could be calculated using Formula (1).

$$
P_{d}=\left(\frac{W_{1}-W_{2}}{W_{1}-W_{0}}\right) \times 100 \%
$$

\subsection{Basic properties of asphalt used in the experiment}

The asphalt used in the experiment was the 90\# asphalt produced by Liaoning Panjin North Asphalt Co., Ltd., the type of the asphalt was consistent with the asphalt used in the Jicao Expressway project. The properties of the asphalt are shown in Table 1.

Table 1. Basic properties of the asphalt

\begin{tabular}{cc}
\hline Property & $90 \#$ Asphalt \\
\hline Penetration grade $\left(25^{\circ} \mathrm{C}, 100 \mathrm{~g}, 5 \mathrm{~s}\right.$, & 86 \\
$0.1 \mathrm{~mm})$ & 150 \\
Ductility $5^{\circ} \mathrm{C}$ & 45 \\
Softening point & 99.97 \\
Solubility $(\%)$ & 302 \\
Flash point $\left(\right.$ open-cup, $\left.{ }^{\circ} \mathrm{C}\right)$ & 1000.3 \\
Density $\left(25^{\circ} \mathrm{C}, \mathrm{kg} / \mathrm{m}^{3}\right)$ & 1.89 \\
Wax content $($ distillation method, \%) & \\
\hline
\end{tabular}

\subsection{Asphalt-aggregate adhesion experiment}

(1) The quartering method was adopted to weigh 100 grams of aggregates between 9.5 and 13.2, then the aggregate samples were put in an oven that had been heated to 5 degrees higher than the mixing temperature $\left(150^{\circ} \mathrm{C}\right)$ of the asphalt for 1 hour, as shown in Figure 1 .

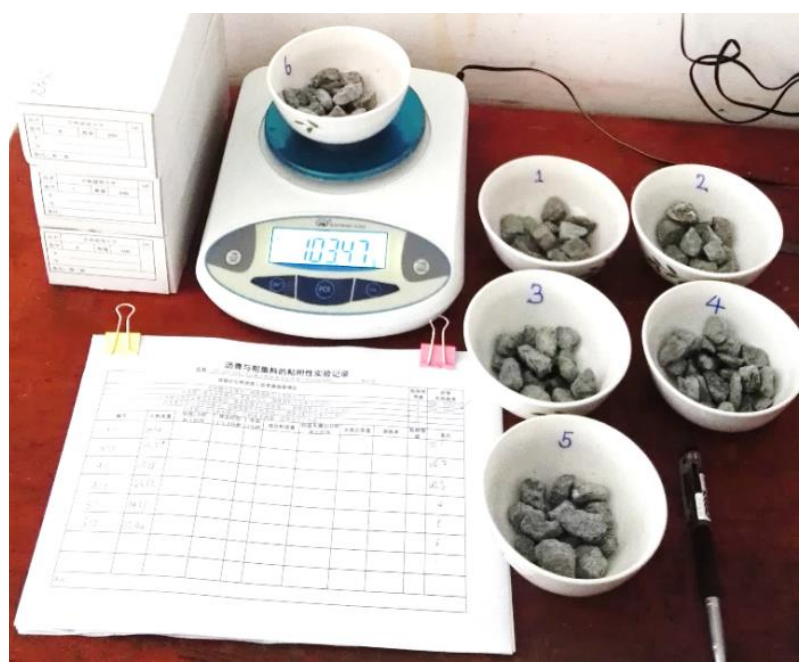

Figure 1. Weigh the aggregates

(2) $5.5 \mathrm{~g}$ of asphalt was weighed and put into a small mixing container, then together with the aggregates, they were put into the oven and heated for 15 minutes, then the aggregates were poured into the asphalt in the container, and immediately mixed for $1 \sim 1.5 \mathrm{~min}$ with a metal shovel, then, 20 pieces of the mixtures were taken out and spread on a glass plate, and cooled at room temperature for 1 hour, as shown in Figure 2.

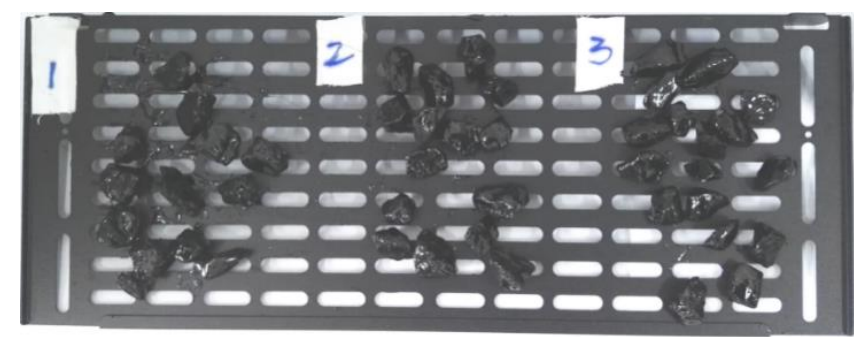

Figure 2. Fully mix the aggregates and the asphalt

(3) The glass plate, together with the aggregates placed on it, were immersed in a constant temperature water tank with a temperature of $80^{\circ} \mathrm{C} \pm 1^{\circ} \mathrm{C}$ for 30 minutes, then, the asphalt floating on the water was collected with a piece of paper, as shown in Figure 3.

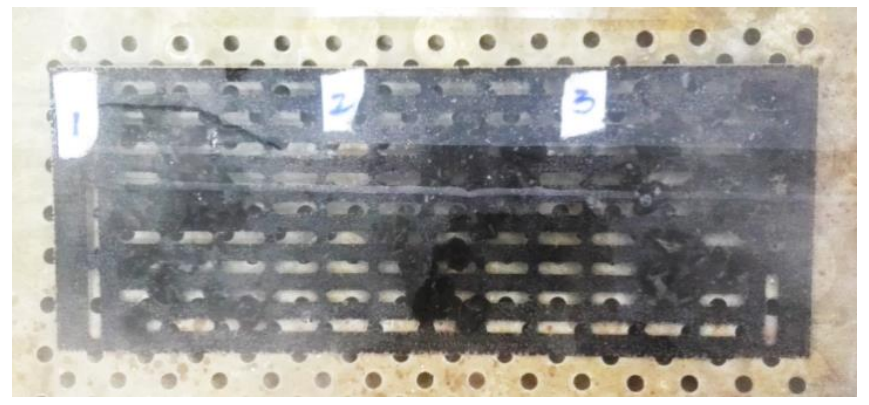

Figure 3. Immerse mixtures in a constant temperature water tank

(4) The glass plate was taken out, cooled at room temperature for 1 hour, and weighed, as shown in Figure 4.

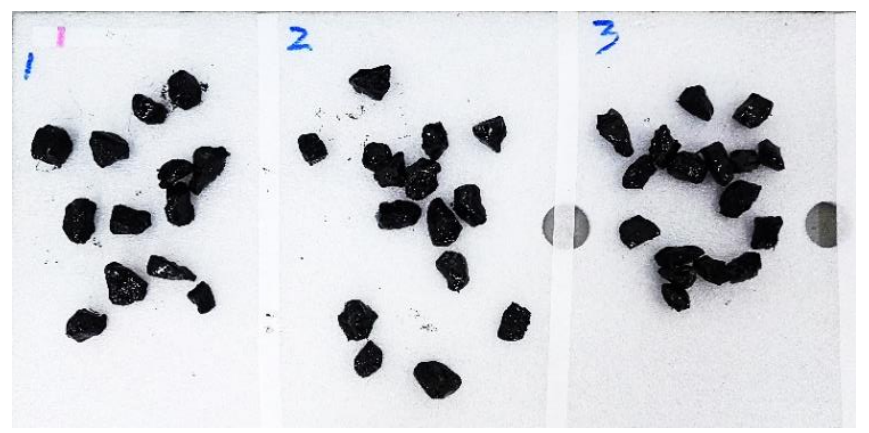

Figure 4. Asphalt mixtures after water immersion experiment

3.4 Peeling rate of asphalt from the surface of basalt, andesite, and limestone aggregates

Based on above experiment, situations of the exfoliation of asphalt adhered to the surface of basalt, andesite, and limestone aggregates could be obtained, as shown in Table 2 .

According to the data in Table 2, we can get a histogram of the peeling rates of asphalt mixtures, as shown in Figure 5.

As can be seen from Figure 5, the peeling rates of limestone were the lowest, the peeling rates of basalt were the highest, and the peeling rates of andesite were in the middle and close to the level of basalt. 
Table 2. Asphalt peeling rates obtained in the water immersion experiment

\begin{tabular}{ccccccccc}
\hline Rock type & No. & Peeling rate & Rock type & No. & Peeling rate & Rock type & No. & Peeling rate \\
\hline \multirow{6}{*}{ Basalt } & X11 & $23.04 \%$ & & A11 & $28.73 \%$ & & S11 & $11.67 \%$ \\
& X12 & $21.34 \%$ & & A12 & $27.47 \%$ & & S12 & $9.78 \%$ \\
& X13 & $24.64 \%$ & & A13 & $31.22 \%$ & & S13 & $13.39 \%$ \\
& X21 & $18.45 \%$ & & A21 & $31.31 \%$ & & S21 & $10.25 \%$ \\
& X22 & $18.44 \%$ & Andesite & A22 & $33.29 \%$ & Limestone & S22 & $13.27 \%$ \\
& X23 & $22.69 \%$ & & A23 & $29.87 \%$ & & S23 & $10.68 \%$ \\
& X31 & $19.85 \%$ & & A31 & $29.80 \%$ & & S31 & $9.83 \%$ \\
& X32 & $24.21 \%$ & & A32 & $30.58 \%$ & & S32 & $12.28 \%$ \\
& X33 & $23.47 \%$ & & A33 & $32.03 \%$ & & S33 & $14.37 \%$ \\
\hline
\end{tabular}

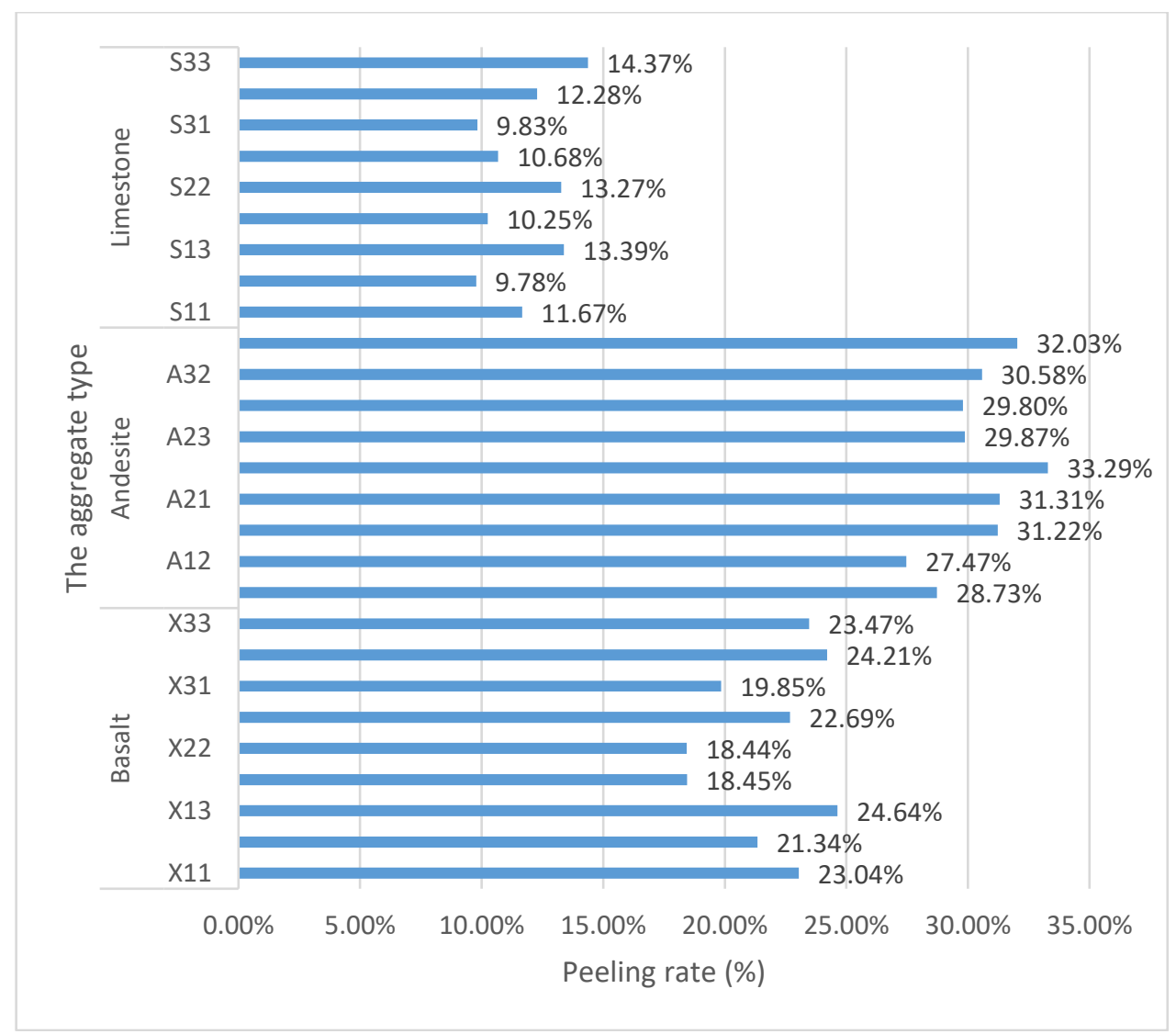

Figure 5. Histogram of the peeling rates of asphalt-coated aggregates

\section{ASPHALT MORTAR-AGGREGATE ADHESION EXPERIMENT}

Asphalt and mineral powder were mixed to form the asphalt mortar, which was taken as the dispersion medium of the asphalt mixtures. After fully mixed and compacted, the asphalt mortar filled in the gap between the coarse and fine aggregates, and wrapped on the surface of the aggregates. The adhesion of asphalt mortar on the surface of crushed stones directly reflects the anti-stripping ability and water damage resistance of the asphalt mixtures. The American Society for Testing and Materials (ASTM) stipulated in its ASTM-D3625 standard [15] to use the water boiling experiment to judge the adhesion of aggregates and asphalt mortar.

\subsection{Peeling rate of asphalt mortar from aggregate surface}

The water immersion method was adopted in the experiment to evaluate the adhesion of asphalt mortar on the surface of aggregates and measure the peeling rate.
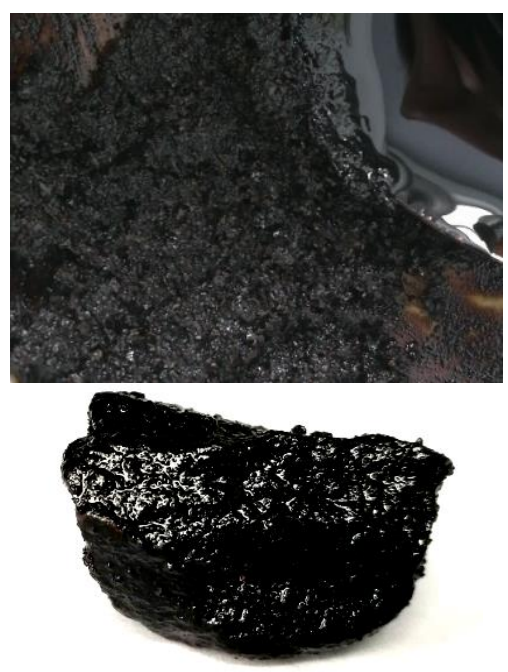

Figure 6. Asphalt mortar and asphalt mortar-coated aggregate 
Steps of the experiment:

(1) Asphalt, mineral powder, and aggregates were heated in a thermostat to the mixing temperature $150^{\circ} \mathrm{C}$ for 1 hour, then the dried aggregates were weighed, and the weight value was recorded as $W_{0}$

(2) Asphalt and mineral powder were mixed into a gelatinous mixture, during the mixing process, the temperature decreased significantly, therefore the mixed asphalt mortar was put back into the thermostat and heated to the mixing temperature for 20 minutes, as shown in Figure 6;

(3) The aggregates were poured into the asphalt mortar and mixed evenly. The mixtures were cooled at room temperature for 1 hour, weighed, the weight value was recorded as $W_{l}$;

(4) The mixtures were put in the constant temperature water tank with a temperature of $80^{\circ} \mathrm{C} \pm 1^{\circ} \mathrm{C}$ for 30 minutes, then taken out and dried at room temperature for 24 hours, weighed, and the weight value was recorded as $W_{2}$. Then, the peeling rate of the asphalt mortar-coated aggregates can be calculated by Formula (2):

$$
P_{d}=\left(\frac{W_{1}-W_{2}}{W_{1}-W_{0}}\right) \times 100 \%
$$
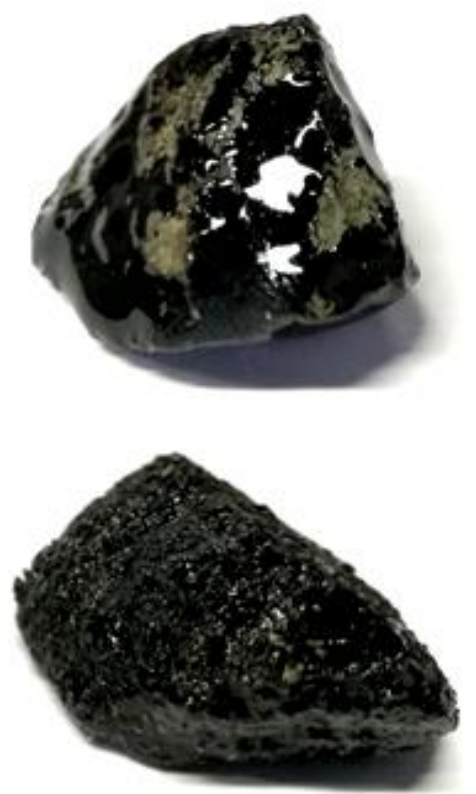

Figure 7. Images of asphalt-coated basalt and asphalt mortarcoated basalt X01 after the water immersion experiment
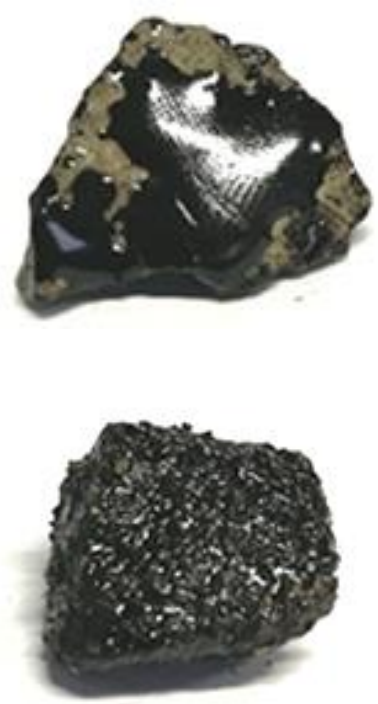

Figure 8. Images of asphalt-coated andesite and asphalt mortar-coated andesite A01 after the water immersion experiment
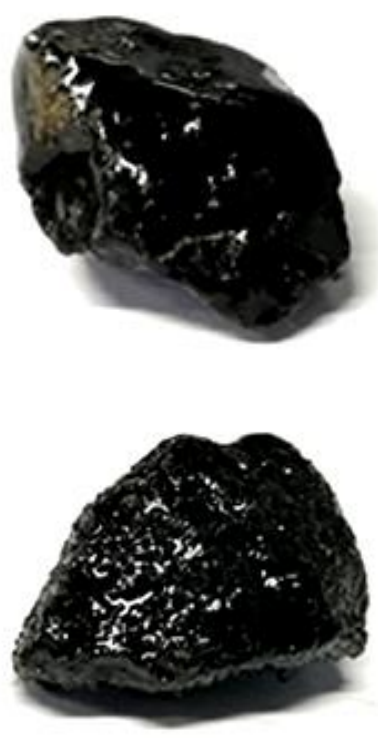

Figure 9. Images of asphalt-coated limestone and asphalt mortar-coated limestone S02 after the water immersion experiment

\subsection{Comparison of peeling rates}

Table 3. Peeling rate of asphalt mortar from aggregate surface (water immersion experiment)

\begin{tabular}{|c|c|c|c|c|c|c|c|c|}
\hline Rock type & No. & Peeling rate & Rock type & No. & Peeling rate & Rock type & No. & Peeling rate \\
\hline \multirow{9}{*}{ Basalt } & $\mathrm{J}-\mathrm{X} 11$ & $13.61 \%$ & \multirow{9}{*}{ Andesite } & J-A11 & $15.40 \%$ & \multirow{9}{*}{ Limestone } & J-S11 & $13.03 \%$ \\
\hline & $\mathrm{J}-\mathrm{X} 12$ & $15.13 \%$ & & J-A12 & $15.03 \%$ & & J-S12 & $12.60 \%$ \\
\hline & $\mathrm{J}-\mathrm{X} 13$ & $16.50 \%$ & & J-A13 & $13.15 \%$ & & $\mathrm{~J}-\mathrm{S} 13$ & $12.18 \%$ \\
\hline & $\mathrm{J}-\mathrm{X} 21$ & $16.45 \%$ & & $\mathrm{~J}-\mathrm{A} 21$ & $20.33 \%$ & & $\mathrm{~J}-\mathrm{S} 21$ & $10.92 \%$ \\
\hline & $\mathrm{J}-\mathrm{X} 22$ & $11.56 \%$ & & $\mathrm{~J}-\mathrm{A} 22$ & $18.13 \%$ & & $\mathrm{~J}-\mathrm{S} 22$ & $11.22 \%$ \\
\hline & $\mathrm{J}-\mathrm{X} 23$ & $12.09 \%$ & & $\mathrm{~J}-\mathrm{A} 23$ & $17.33 \%$ & & $\mathrm{~J}-\mathrm{S} 23$ & $12.38 \%$ \\
\hline & $\mathrm{J}-\mathrm{X} 31$ & $14.77 \%$ & & J-A31 & $15.45 \%$ & & J-S31 & $9.98 \%$ \\
\hline & $\mathrm{J}-\mathrm{X} 32$ & $13.91 \%$ & & $\mathrm{~J}-\mathrm{A} 32$ & $18.76 \%$ & & $\mathrm{~J}-\mathrm{S} 32$ & $12.32 \%$ \\
\hline & $\mathrm{J}-\mathrm{X} 33$ & $14.10 \%$ & & J-A33 & $16.30 \%$ & & $\mathrm{~J}-\mathrm{S} 33$ & $9.05 \%$ \\
\hline
\end{tabular}


Based on above experiment, The peeling status of the asphalt and asphalt mortar is shown in Figures 7, 8 and 9. The peeling rate of asphalt mortar from aggregate surface of basalt, andesite, and limestone aggregates could be obtained, as shown in Table 3.

As can be seen from Table 3 and Figure 10, the peeling rates of asphalt mortar from aggregate surface were quite close, the peeling rates of asphalt mortar from andesite surface were slightly higher than those of basalt and limestone. The adhesion of limestone was the best, and the peeling rates of limestone were the lowest, which was of equal level with the peeling rates of asphalt from aggregate surface.

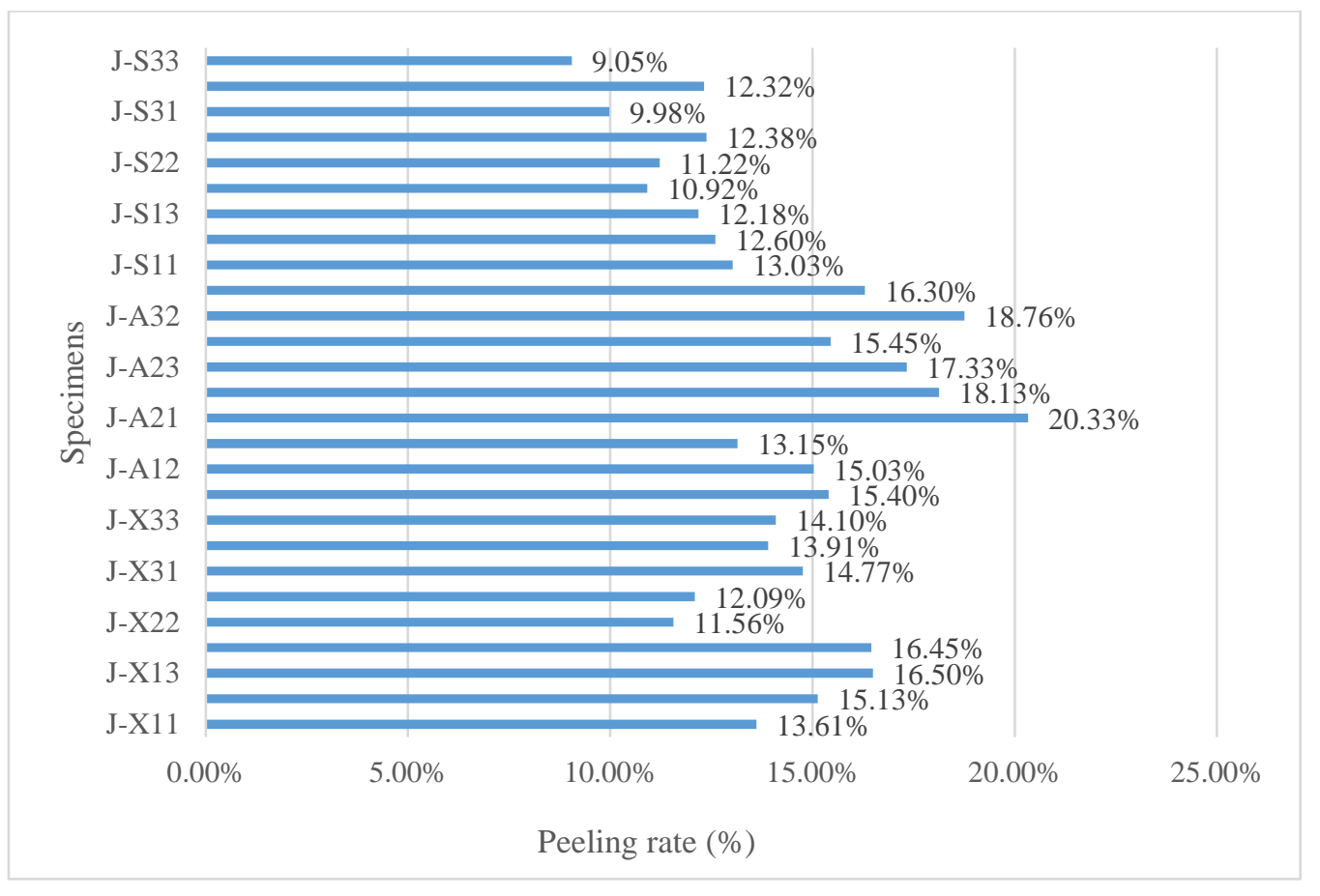

Figure 10. Histogram of the peeling rates of asphalt mortar-coated aggregates

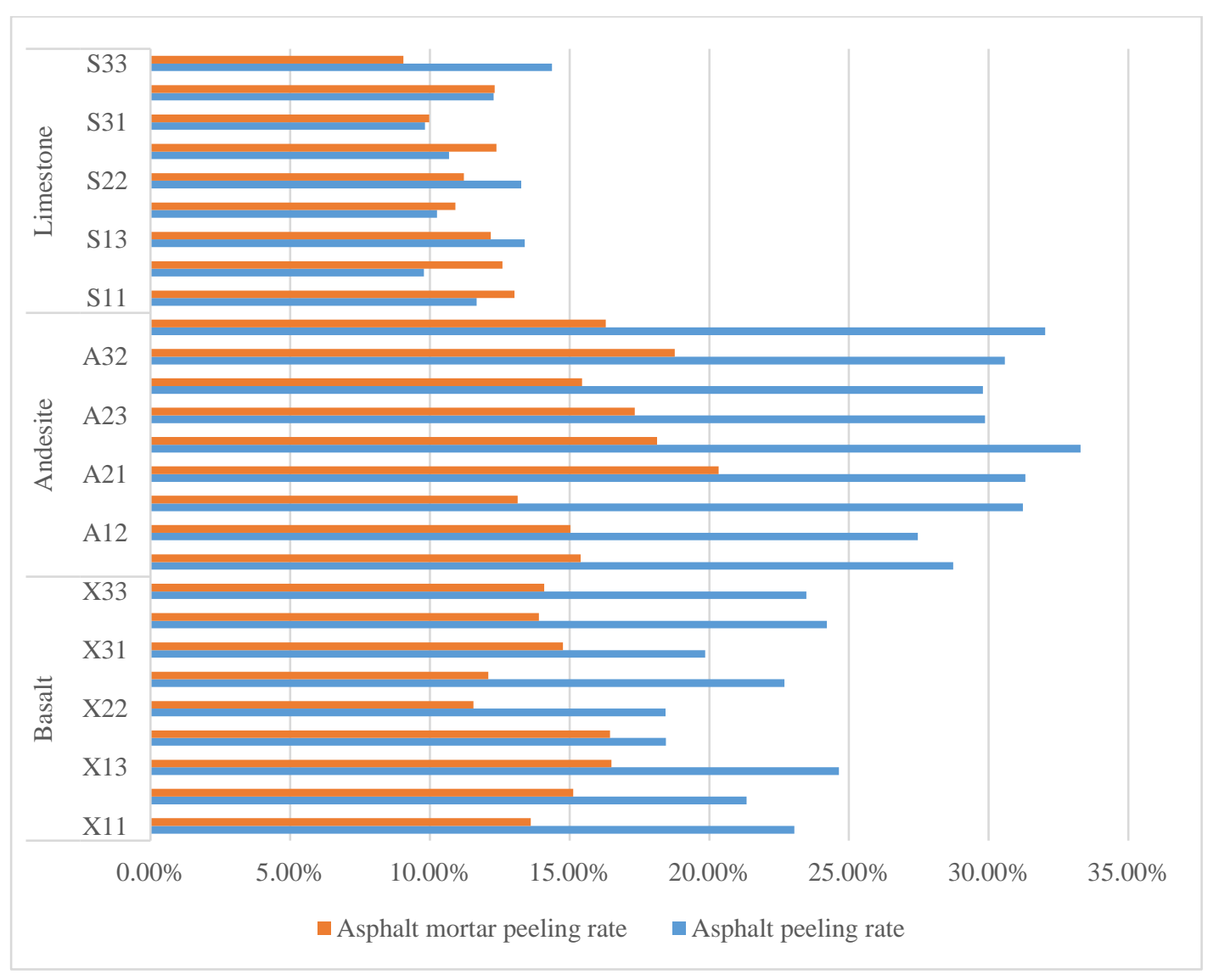

Figure 11. Histogram of the peeling rates of asphalt and asphalt mortar 


\subsection{Comparison of adhesion of asphalt and asphalt mortar on aggregate surface}

The peeling rates of asphalt-coated aggregates and asphalt mortar-coated aggregates were plotted together in the histogram of Figure 11, as can be seen in the figure, the peeling rates of asphalt and asphalt mortar from limestone were close. The peeling rates of asphalt mortar from basalt and andesite were much lower than those of asphalt. For basalt aggregates, the peeling rates of asphalt mortar were reduced by an average of $34 \%$ compared with the peeling rates of asphalt; as for andesite, the peeling rates of asphalt mortar were reduced by an average of $45 \%$ compared with the peeling rates of asphalt On the whole, asphalt mortar can better adhere to aggregate surface than pure asphalt.

\section{CHARACTERISTICS OF THE MICROSCOPIC IMAGES OF THE INTERFACE BETWEEN ASPHALT/ASPHALT MORTAR AND CRUSHED STONES}

According to above analysis, the peeling rates of asphalt mortar from crushed stone surface were much lower than those of asphalt. Observation through electron microscope showed that after the water immersion experiment, asphalt mortar maintained a good coating effect, while on the surface of crushed stones coated by pure asphalt, there're mottled areas and even large-area asphalt peeling off, as shown in Figure 12 below.

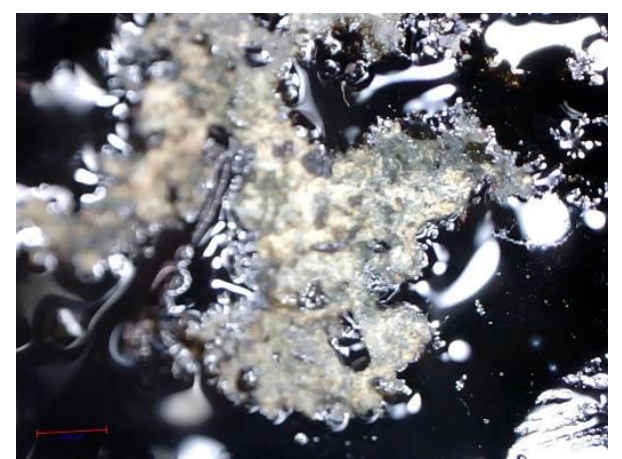

(a) Exfoliation of asphalt-coated crushed stone

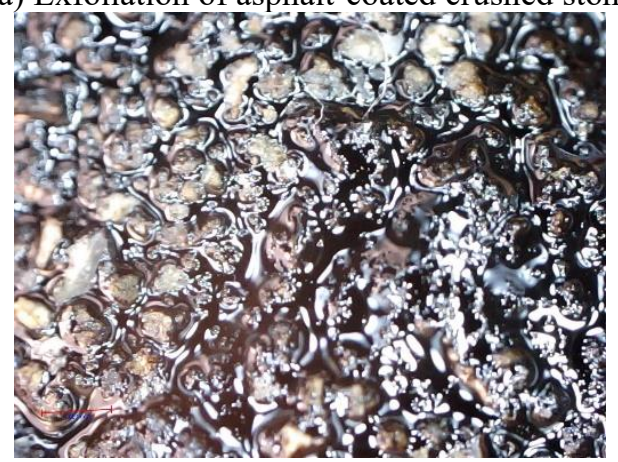

(b) Exfoliation of asphalt mortar-coated crushed stone

Figure 12. Microscopic images after water immersion experiment

\subsection{Sample preparation and profile image acquisition}

To observe the adhesion of asphalt and asphalt mortar on the surface of crushed stones more directly, an electron microscope was used to magnify the profile of the crushed stones coated with asphalt and asphalt mortar and analyze the status of the adhesion of mineral powder, asphalt, and aggregates. At first, the aggregates and asphalt were fully mixed at the mixing temperature and placed at room temperature for 24 hours to ensure that the aggregates were naturally and fully cooled. Since asphalt is sensitive to temperature, if the profile is formed by the cutting of an angle grinder, the high temperature produced by the friction between the angle grinder and the asphalt during the cutting process would destroy the coating state of asphalt (asphalt mortar) on the surface of the crushed stones, therefore, in the experiment, a hammer was used to break the stone coated with asphalt (asphalt mortar) into 2 to 4 pieces, then a sample with a flat section was selected for microscopic image observation, as shown in Figure 13

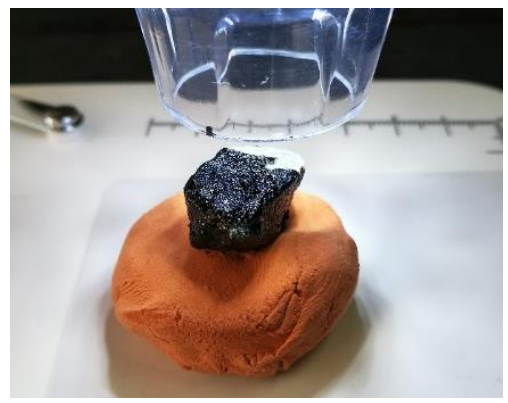

Figure 13. Microscopic image observation of the section of asphalt-coated crushed stone

5.2 Microscopic images of the profile of the interface between asphalt/asphalt mortar and aggregates

As can be seen from Figure 14, asphalt evenly adhered on the surface of the aggregates, and the asphalt layer adhered to the protrusions on the surface of the aggregates was slightly thinner.

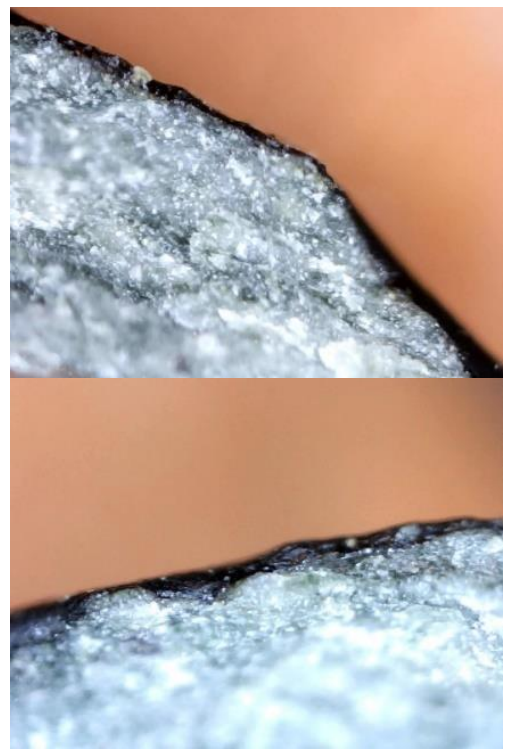

Figure 14. Profile of asphalt adhering on aggregate surface

In Figure 15, mineral powder particles and asphalt mortar were mixed and adhered to the surface of the aggregates. Mineral powder particles distributed randomly at both smooth and rough positions, and the asphalt layer distributed around the mineral powder particles was thicker. 


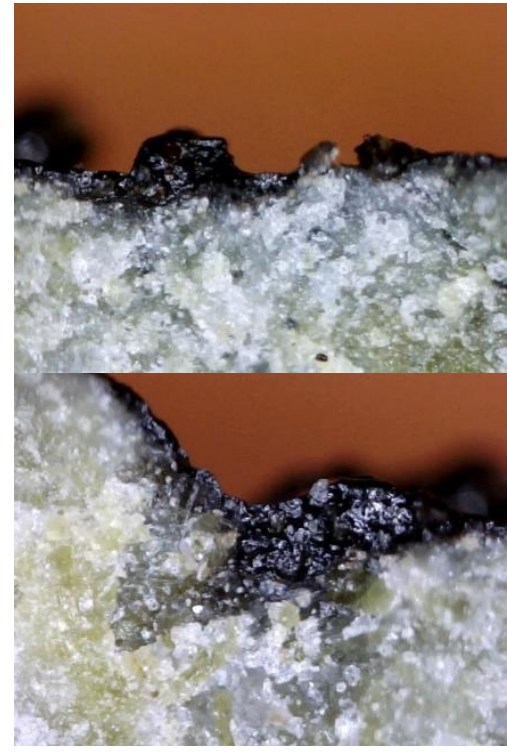

Figure 15. Profile of asphalt mortar adhering on aggregate surface

\subsection{Effect of mineral powder on the adhesion of aggregates and asphalt}

In Figure 16, we marked two protrusions of mineral powder particles and asphalt, as can be seen in the figure, the asphalt layer around the mineral powder particles was obviously thicker, mineral powder particles distributed randomly and unevenly, not only adhering to sunken positions of rough surface, but also adhering to flat surface positions.

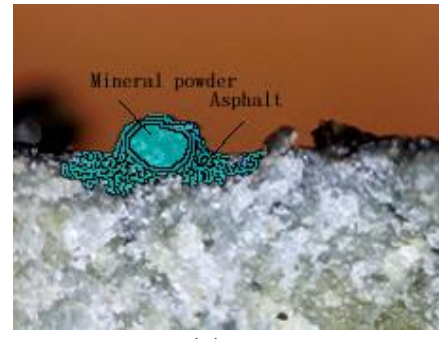

(a)

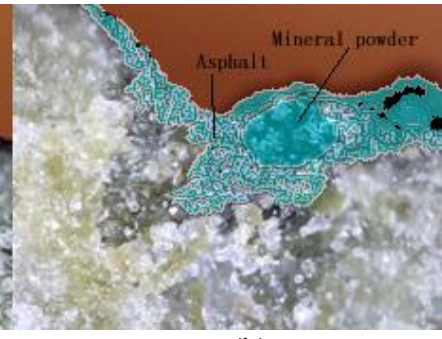

(b)
Figure 16. Adhesion positions of mineral powder particles

Figure 16 shows the adhesion positions of the mineral powder particles, since the particles were very small, they were in a suspended state in the asphalt mortar. Mineral powder particles enhanced the adhesion of asphalt on the aggregate surface: the particles formed an embedding and wedging structure in the surface texture of the aggregates, which was equivalent to indirectly increasing the roughness of the aggregate surface and increasing the adhesion thickness of the asphalt on the aggregate surface. A thicker asphalt layer was also formed at the edge of the mineral powder, which improved the mixture's ability to resist water damage, especially in large pores and texture structure on the aggregate surface, the mineral powder particles can stabilize the embedding and wedging structure and act as filler, as shown in Figure 16 (b).

Compared with the direct adhesion of asphalt and aggregate surface, the adhesion structure of asphalt mortar on aggregate surface can be divided into four layers: the aggregate surface and asphalt structure layer, the asphalt and mineral powder particle structure layer, the mineral powder particle and asphalt structure layer, and the asphalt and air structure layer, as shown in Figure 17. Compared with the direct-contact interface between asphalt and aggregates, the structure of surface/interface of asphalt mortar and aggregates is more complicated and the adhesion level is higher.

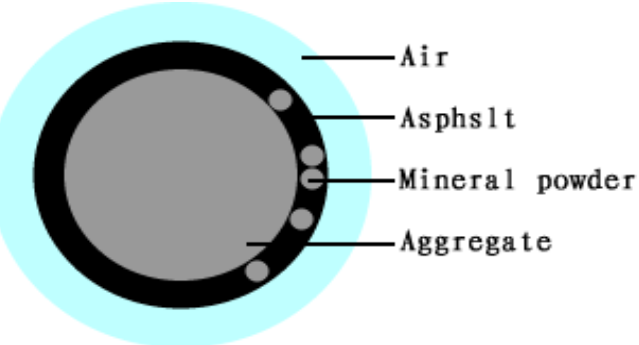

Figure 17. Adhesion state of asphalt mortar on the aggregate surface

$90 \%$ of the particles in the mineral powder had a diameter less than $0.075 \mathrm{~mm}, 10 \%$ of the particles had a diameter between $0.075 \mathrm{~mm}$ and $0.6 \mathrm{~mm}$, as shown in Figure 18 .

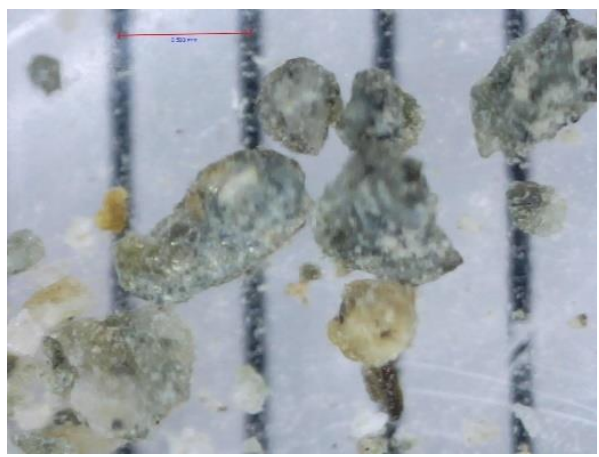

Figure 18. A microscopic image of the mineral powder

The rough texture of aggregate surface and the size of mineral powder particles together increased the contact area between the mineral powder and the aggregates, under the action of the asphalt in the gap, it formed a better asphaltaggregate adhesion state. In the asphalt mixtures, the surface/interface effect of asphalt and aggregates changed from a simple three-phase interaction state of air-asphaltaggregate to a complex multi-phase interaction state of airasphalt-mineral powder-asphalt-aggregate. Thus it can be seen that, a reasonable compatibility of aggregates, fine aggregates, mineral powder, and asphalt has a great impact on the adhesion and road performance of the asphalt mixtures.

\section{CONCLUSION}

Experiment conducted in this study showed that, compared with pure asphalt, the asphalt mortar could bind with aggregates more firmly. Microscopic images showed that the mineral powder particles and asphalt mortar were mixed and adhered to the surface of the aggregates together, and mineral powder particles distributed randomly at both smooth and rough positions. The profile images also showed that the asphalt layer distributed around mineral powder particles was thicker, mineral powder increased the roughness of aggregate surface, thereby increasing the adhesion thickness of asphalt on aggregate surface. Due to the participation of mineral powder, the surface/interface effect of asphalt mixtures 
formed a complicated joint-action state of air-asphalt-mineral powder-asphalt-aggregate. More asphalt could be adhered to the aggregate surface, and the asphalt layer was thicker, which can effectively reduce the water damage, and this result and the water immersion experiment result had verified each other

\section{ACKNOWLEDGMENTS}

This study was supported by the 13th Five-Year science of the Education Department in Jilin Province (Grant No.: JJKH20200287KJ) and Jilin Education Science Planning Project (Grant No.: GH19214).

\section{REFERENCES}

[1] Rateke, T., Von Wangenheim, A. (2021). Road surface detection and differentiation considering surface damages. Autonomous Robots, 45(2): 299-312. https://doi.org/10.1007/s10514-020-09964-3

[2] Tian, P., Shukla, A., Nie, L., Zhan, G., Liu, S. (2018). Characteristics' relation model of asphalt pavement performance based on factor analysis. International Journal of Pavement Research and Technology, 11(1): 112. https://doi.org/10.1016/j.ijprt.2017.07.007

[3] Shim, S., Cho, G.C. (2020). Lightweight semantic segmentation for road-surface damage recognition based on multiscale learning. IEEE Access, 8: 102680-102690. https://doi.org/10.1109/ACCESS.2020.2998427

[4] Tudor, B.D. (2019). Improving the properties of the asphalt mixture, by content variation of the bitumen. The Annals of "Dunarea de Jos" University of Galati. Fascicle IX, Metallurgy and Materials Science, 42(2): 27-31. https://doi.org/10.35219/mms.2019.2.05

[5] Hassan, H.M.Z., Wu, K., Huang, W., Chen, S., Zhang, Q., Xie, J., Cai, X. (2021). Study on the influence of aggregate strength and shape on the performance of asphalt mixture. Construction and Building Materials, 294:

https://doi.org/10.1016/j.conbuildmat.2021.123599

[6] Lagos-Varas, M., Movilla-Quesada, D., Arenas, J.P., Raposeiras, A.C., Castro-Fresno, D., Calzada-Pérez, M.A., Maturana, J. (2019). Study of the mechanical behavior of asphalt mixtures using fractional rheology to model their viscoelasticity. Construction and Building Materials, 200:

124-134. https://doi.org/10.1016/j.conbuildmat.2018.12.073

[7] Xu, J., Zheng, C. (2021). Random generation of asphalt mixture mesostructure and thermal-mechanical coupling analysis at low temperature. Construction and Building Materials, 280(3): https://doi.org/10.1016/j.conbuildmat.2021.122537

[8] Wang, H., Huang, W., Cheng, J., Ye, G. (2021). Mesoscopic creep mechanism of asphalt mixture based on discrete element method. Construction and Building Materials, 272:

121932.

https://doi.org/10.1016/j.conbuildmat.2020.121932

[9] Bahmani, H., Sanij, H.K., Peiravian, F. (2021). Estimating Moisture Resistance of asphalt mixture containing epoxy resin using Surface Free Energy Method and Modified Lottman test. International Journal of Pavement Engineering, 1-13. https://doi.org/10.1080/10298436.2021.1904236
[10] Bi, Y., Guo, F., Zhang, J., Pei, J., Li, R. (2021). Correlation analysis between asphalt binder/asphalt mastic properties and dynamic modulus of asphalt mixture. Construction and Building Materials, 276: 122256.

https://doi.org/10.1016/j.conbuildmat.2021.122256

[11] Alvarez, A.E., Gomez, K.L., Gomez, D.C., Reyes-Ortiz, O.J. (2019). Optimising the effect of natural filler on asphalt-aggregate interfaces based on surface free energy measurements. Road Materials and Pavement Design, 20(7): $1548-1570$. https://doi.org/10.1080/14680629.2018.1465451

[12] Ahmad, K.A., Hassan, N.A., Abdullah, M.E., Bilema, M.A., Usman, N., Hainin, M.R.B. (2019). Image processing procedure to quantify the internal structure of porous asphalt concrete. Multidiscipline Modeling in Materials and Structures. 15(1): 206-226. https://doi.org/10.1108/MMMS-08-2017-0073

[13] Latifi, H., Amini, N. (2020). Effect of aggregate type on moisture susceptibility of modified cold recycled mix asphalt: evaluation by mechanical tests and Surface Free Energy method. Frattura ed Integrità Strutturale, 14(52): 211-229.

[14] Ali, S.A., Zaman, M., Ghabchi, R., Rahman, M.A., Ghos, S., Rani, S. (2020). Effect of additives and aging on moisture-induced damage potential of asphalt mixes using surface free energy and laboratory-based performance tests. International Journal of Pavement Engineering, $1-12$. https://doi.org/10.1080/10298436.2020.1742335

[15] Moraes, R., Velasquez, R., Bahia, H. (2017). Using bond strength and surface energy to estimate moisture resistance of asphalt-aggregate systems. Construction and Building Materials, 130: 156-170. https://doi.org/10.1016/j.conbuildmat.2016.10.043

[16] Swamy, A.K., Matolia, V., Singh, P., Ramana, G.V. (2018). Effect of test geometry and aggregate texture on angle of repose of aggregates. Journal of Testing and Evaluation, 47(6): 4296-4308. https://doi.org/10.1520/JTE20170460

[17] El Sawda, C., Fakhari-Tehrani, F., Absi, J., Allou, F., Petit, C. (2019). Multiscale heterogeneous numerical simulation of asphalt mixture. Material Design \& Processing Communications, 1(3): e42. https://doi.org/10.1002/mdp2.42

[18] Karimi, M.M., Jahanbakhsh, H., Nejad, F.M. (2021). Energy-based approach to characterize induced heating of asphalt concrete under electromagnetic field. Construction and Building Materials, 273: 121762. https://doi.org/10.1016/j.conbuildmat.2020.121762

[19] Sun, W., Wang, H. (2020). Moisture effect on nanostructure and adhesion energy of asphalt on aggregate surface: A molecular dynamics study. Applied Surface Science, $\quad$ 510: 145435. 10.1016/j.apsusc.2020.145435

[20] Pape, S., Lee, K., Castorena, C., Kim, Y.R. (2018). Optimization of the laboratory fabrication of small specimens for asphalt mixture performance testing. Transportation Research Record, 2672(28): 438-450. https://doi.org/10.1177/0361198118790845

[21] Adolfo, F.R., do Nascimento, P.C., Bohrer, D., Viana, C., de Carvalho, L.M., Cravo, M.C.C., Nascimento, L. (2020). Extraction induced by emulsion breaking for simultaneous determination of $\mathrm{Co}, \mathrm{Fe}$ and $\mathrm{Ni}$ in 
petroleum asphalt cement by high-resolution continuum source atomic absorption spectrometry. Fuel, 277: 118098. https://doi.org/10.1016/j.fuel.2020.118098

[22] Makowska, M., Pellinen, T. (2021). Thin layer chromatography performed in stages to identify the presence of aromatic like fraction in chosen bitumen modifiers. Journal of Traffic and Transportation Engineering (English Edition), 8(3): 453-466. https://doi.org/10.1016/j.jtte.2019.09.008

[23] Boysen, R.B., Schabron, J.F. (2013). The automated asphaltene determinator coupled with saturates, aromatics, and resins separation for petroleum residua characterization. Energy \& Fuels, 27(8): 4654-4661. https://doi.org/10.1021/ef400952b

[24] Jadidi, K., Khalili, M., Karakouzian, M. (2021). Feasibility of using non-destructive ultrasound measurement technique to evaluate binder content of asphalt mixtures. CivilEng, 2(2): 396-405. https://doi.org/10.3390/civileng2020022

[25] Kofteci, S., Nazary, M. (2018). Experimental study on usability of various construction wastes as fine aggregate in asphalt mixture. Construction and Building Materials, 185:

369-379. https://doi.org/10.1016/j.conbuildmat.2018.07.059

[26] Awed, A.M., Tarbay, E.W., El-Badawy, S.M., Azam, A.M. (2020). Performance characteristics of asphalt mixtures with industrial waste/by-product materials as mineral fillers under static and cyclic loading. Road Materials and Pavement Design, 1-23. https://doi.org/10.1080/14680629.2020.1826347

[27] Lebedev, M.S., Kozhukhova, M.I., Yakovlev, E.A. (2021). The effect of composition and fineness of mineral fillers on structure of asphalt binder. In Materials Science $\quad$ Forum, 1017: 81-90. https://doi.org/10.4028/www.scientific.net/MSF.1017.8 1

[28] Mukhtar, N., Hasan, M.R.M., Ghazali, M.F.H.M., Zin, Z.M., Shariff, K.A., Sani, A. (2021). Influence of concentration and packing of filler particles on the stiffening effect and shearing behaviour of asphalt mastic. Construction and Building Materials, 295: 123660. https://doi.org/10.1016/j.conbuildmat.2021.123660 